\title{
The Colonization Process of Sunflower by a Green Fluorescent Protein-Tagged Isolate of Verticillium dahliae and its Seed Transmission
}

Y. Zhang, J. Zhang, J. Gao, and G. Zhang, College of Agronomy, Inner Mongolia Agricultural University, Hohhot, China; Y. Yu, College of Forestry Protection, Beijing Forestry University, Beijing, China; H. Zhou, College of Agronomy, Inner Mongolia Agricultural University; W. Chen, United States Department of Agriculture-Agricultural Research Service, Washington State University, Pullman; and J. Zhao, ${ }^{\dagger}$ College of Agronomy, Inner Mongolia Agricultural University

\begin{abstract}
Sunflower Verticillium wilt is a widespread and destructive disease caused by the soilborne pathogen Verticillium dahliae. To better understand the process of infection and seed transmission of the fungus, sunflower roots were inoculated with a $V$. dahliae strain (VdBM9-6) labeled with green fluorescent protein (GFP) and monitored microscopically. After 24 to $96 \mathrm{~h}$ postinoculation (hpi), conidia germinated and developed into mycelium on root hairs, elongation zones, and caps of lateral roots. Mycelium colonized vascular bundles of lateral roots and taproots at 7 days postinoculation (dpi). At 10 weeks postinoculation

(wpi), the epidermal cells, cortical tissues, and vascular elements of stem, petiole, and leaf veins were colonized by mycelium. By 12 wpi, strong GFP signals were detected not only on different tissues of inflorescence but also on testa of seed and a small fraction of pollen grains. A GFP signal was not observed on cotyledon tissues in the seed. Additionally, the colonization of $V$. dahliae on testa was also confirmed with MNP-10 selection medium, indicating that the testa of seed is the main carrier for the long distance transmission of sunflower yellow wilt.
\end{abstract}

Sunflower (Helianthus annuus L.) is one of the main oilseed crops in the world. In China, it is the fourth most widely grown oilseed crop, with a total cultivation area of approximately 1.2 million ha. Inner Mongolia is the largest sunflower production region within China, accounting for around 0.7 million ha (Lan et al. 2009). Sunflower Verticillium wilt, caused by the fungus Verticillium dahliae Kleb., has recently became one of the most important diseases in China.

Verticillium wilt was described as "leaf mottle" in 1948. Prior to the early 1970s, the Verticillium spp. on sunflower were identified as Verticillium albo-atrum Reinke \& Berthold (Sackston et al. 1957) but later recognized as V. dahliae (Devaux and Sackston 1966). Characteristic symptoms of Verticillium infection usually appear as "leaf mottle" at or near the flowering stage. Sackston et al. (1957) first described the symptoms on sunflower as a mottled appearance based on the color contrast between the yellow and the persisting green areas of leaves (Sackston et al. 1957). Leaf mottling and chlorosis on bottom leaves was observed first; then, the chlorotic patches gradually enlarged, coalesced, turned brown, and became necrotic (Harveson et al. 2016; Markell et al. 2015). Symptoms progress upward and are followed by wilting of the whole plant. Discoloration of the vascular bundles is always observed in the infected stems (Ren et al. 2014).

V. dahliae is a soilborne organism and overwinters as microscle rotia in plant residue. Root exudates of the host could break the dormancy of microsclerotia and stimulate germination and production of hyphae (Fitzell et al. 1980). The hyphae reached to the hair roots

${ }^{\dagger}$ Corresponding author: J. Zhao; E-mail: zhaojun@imau.edu.cn

Y. Zhang and J. Zhang contributed equally to this work.

Funding: This work was funded by the China Agricultural Research System (CARS-14) and Special Fund for Agro-scientific Research in the Public Interest (number 201503109).

*The $\boldsymbol{e}$-Xtra logo stands for "electronic extra" and indicates that four supplementary figures are published online.

Accepted for publication 28 March 2018.

C) 2018 The American Phytopathological Society of the host and penetrated into host cells directly or by producing specific structures such as appressoria. Vallad and Subbarao (2008) observed appressoria at the junction of epidermal cells of host roots during infection of $V$. dahliae on lettuce. In oilseed rape (Eynck et al. 2007) and Arabidopsis thaliana (Zhao et al. 2014), hyphae were only slightly swollen at the tip, instead of forming appressoria, when $V$. dahliae invaded root tissues. A slight swelling of the hyphae followed by the formation of a narrow infection peg during $V$. dahliae perforation was also observed in cotton roots (Zhao et al. 2014). After invasion of the epidermal cells, $V$. dahliae colonizes inside the root cortical tissue and penetrates into the xylem. It is generally assumed that the conidia move acropetally along with the host plant transpiration, thus invading the stem tissue of the host and, eventually, infecting the entire plant (Zhang et al. 2013).

$V$. dahliae can be transmitted as conidia or microsclerotia through vegetative propagation materials, soil carried on footwear, farm equipment, or irrigation water (Zhang et al. 2013). Also, microscle rotia can contaminate the exterior of sunflower seed and fungal mycelium can be found within seed, particularly on the pericarp and testa, but not on cotyledons (Sackston 1980; Sackston et al. 1957). In addition to sunflower, $V$. dahliae has been reported to colonize the seed of lettuce (Lactuca sativa L.) (Vallad and Subbarao 2008), spinach (Spinacia oleracea L.) (du Toit et al. 2005), and safflower (Carthamus tinctorius L.) (Klisiewicz 1975). Seedborne transmission of $V$. dahliae may play an important role in the epidemiology of Verticillium wilt on different hosts such as lettuce (Vallad and Subbarao 2008), spinach (Maruthachalam et al. 2013), cotton (Allen 1951), eggplant (Kadow 1934), and safflower (Klisiewicz 1975).

Losses from Verticillium wilt can be economically significant. Hoes and Putt (1963) estimated that yield losses of sunflower ranged from 50 to $100 \%$ in inspected fields in Manitoba, Canada. The incidence of sunflower Verticillium wilt ranged from 10 to $30 \%$ and caused significant losses since 2011 in the Inner Mongolia region of China (data from China Sunflower Research System). The rapid dispersal of $V$. dahliae throughout sunflower production areas in China prompted us to consider the possible role of seed transmission. Results from previous studies provide evidence that the ovary can be colonized by different kinds of fungi, including $V$. dahliae, via infected vascular system of the female flower (Maruthachalam et al. 2013; Selden and Schatz 1989; Vallad and Subbarao 2008). The objectives of this study were to characterize the infection process of $V$. dahliae on sunflower, determine whether $V$. dahliae colonizes 
sunflower seed, and identify which parts of the seed tissues can be infected. Our findings will lay a foundation for controlling the sunflower Verticillium wilt via seed treatment.

\section{Materials and Methods}

$V$. dahliae transformation. V. dahliae strain VdBM9 was isolated from a diseased sunflower plant, collected from Wuyuan Town, Bayannaoer City, Inner Mongolia, China. Agrobacterium tumefaciens strain LBA4404, which was kindly provided by Dr. Baolong Zhang (Jiangsu Academy of Agricultural Sciences, Nanjing, China), contains the binary vector pGH-sGFP and a T-DNA that harbors the green fluorescent protein (GFP) and hygromycin B resistance genes. Transformation of $V$. dahliae was performed as described by Dobinson et al. (2004) with minor modifications.

VdBM9 was cultured on potato dextrose agar (PDA) medium at $25^{\circ} \mathrm{C}$ for 7 days to obtain conidia for transformation. A single colony was taken from a 48-h-old culture old of LBA4404 on a yeast extract broth (YEB) plate and transferred into liquid minimal medium (MM) (Zhang et al. 2017) and incubated for $48 \mathrm{~h}$ in a shaker-incubator (HZQ-X100; Jiangsu, China) at $220 \mathrm{rpm}$. Both YEB and MM contained rifampicin and kanamycin and were incubated at $28^{\circ} \mathrm{C}$. The culture was centrifuged at $2,380 \times g$ for $5 \mathrm{~min}$, the pellet was washed three times with induction media (IM) (Zhang et al. 2017), then resuspended in IM containing $200 \mu \mathrm{M}$ acetosyringone and adjusted to an optical density at $600 \mathrm{~nm}$ of 0.15 to 1.20 . After incubating for an additional $6 \mathrm{~h}$ at $28^{\circ} \mathrm{C}$ and $200 \mathrm{rpm}$, the bacterial cells were mixed with an equal volume of conidia of $V$. dahliae $\left(1 \times 10^{6}\right.$ conidia/ml $)$. An aliquot $(200 \mu \mathrm{l})$ of the mixture was sprayed onto cellophane membrane placed on top of cocultivation medium plate (Zhang et al. 2017). After cocultivation for $48 \mathrm{~h}$, the cellophane membranes were transferred onto selection medium (Zhang et al. 2017) containing hygromycin B $(50 \mu \mathrm{g} / \mathrm{ml})$. Putative transformants were transferred onto PDA plate with hygromycin B $(50 \mu \mathrm{g} / \mathrm{ml})$ and incubated at $25^{\circ} \mathrm{C}$ for 5 days. After three serial transfers to the selective media, the putative transformants were examined under an Olympus BX51 compound microscope linked to a CCD device. The microscope was equipped with filters for observing GFP (Longpass Endow GFP [450 to $490 \mathrm{~nm}$ excitation, $500 \mathrm{~nm}$ bandpass emission], Bandpass Endow GFP [450 to $490 \mathrm{~nm}$ excitation, 500 to $550 \mathrm{~nm}$ bandpass emission], and a Blue longpass [450 to $490 \mathrm{~nm}$ excitation, $515 \mathrm{~nm}$ longpass emission]). Positive colonies were subcultured at least seven times on PDA medium and checked under epifluorescence microscopy to ensure stable expression of GFP in $V$. dahliae.

Molecular identification of positive transformants. DNA was isolated from mycelia of 6-day-old cultures on potato dextrose broth at $25^{\circ} \mathrm{C}$. Mycelia were harvested by filtration through Whatman grade 1 filter paper, lyophilized for $24 \mathrm{~h}$, then ground into a fine powder with a mortar and pestle. The mycelium powder $(100 \mathrm{mg})$ was transferred into a 1.5-ml microcentrifuge tube and DNA was isolated using a cetyltrimethylammonium bromide extraction method (Stewart and Via 1993). Polymerase chain reaction (PCR) was performed by using hygromycin B gene-specific primer pair Hy-F/Hy-R (Hy-F: 5'-GATGTAGGAGGGCGTGGATA-3' and Hy-R: 5'-CTCTGA TAGATTGGTCAAG-3') and GFP-specific primer pair GFP-F/GFP-R (GFP-F: 5'-GACGTAAACGGCCACAAGTT-3' and GFP-R: 5'GAACTCCAGCAGGACCATGT-3'). The amplification was performed with a Gene Pro Thermal Cycler (BIOER) in a $25-\mu l$ reaction containing $1 \mu \mathrm{l}$ of each primer $(10 \mu \mathrm{M}), 2.5 \mathrm{U}$ of Taq DNA polymerase (Tiangen), $2 \mu \mathrm{l}$ of dNTP $(2.5 \mathrm{mM}), 2.5 \mu \mathrm{l}$ of $10 \times$ PCR buffer, $17 \mu l$ of distilled water, and $1.0 \mu \mathrm{l}$ of template DNA (50 ng). The temperature profile was $94^{\circ} \mathrm{C}$ for $5 \mathrm{~min}$, followed by 35 cycles of $94^{\circ} \mathrm{C}$ for $40 \mathrm{~s}, 60^{\circ} \mathrm{C}(\mathrm{Hy}-\mathrm{F} / \mathrm{Hy}-\mathrm{R})$ or $56^{\circ} \mathrm{C}$ (GFP-F/GFP-R) for $40 \mathrm{~s}$, and $72^{\circ} \mathrm{C}$ for $40 \mathrm{~s}$; and final extension at $72^{\circ} \mathrm{C}$ for $10 \mathrm{~min}$. PCR products were separated on a $1 \%$ agarose gel, stained with Gelview (BioTeke), and photographed.

Phenotypic characterization of GFP transformants. GFP transformants were compared with the wild-type strain for growth rate, fecundity, total crude toxin production, and virulence. For growth rate, colony diameter was measured daily for 7 days. For fecundity, conidia were washed from 7-day-old culture plates with $10 \mathrm{ml}$ of distilled water and conidial concentration was determined with a hemocytometer. For quantification of the total crude toxin production, transformants of $V$. dahliae were grown as a shake culture in $50 \mathrm{ml}$ of Czapek dox broth (CDB) medium (Zhang et al. 2017) at $25^{\circ} \mathrm{C}$ for 10 days at $220 \mathrm{rpm}$. Culture filtrates were harvested through three layers of sterilized cheese cloth and centrifuged at $13,400 \times g$ for $20 \mathrm{~min}$ in $28^{\circ} \mathrm{C}$. The resulting supernatant was filtered through a $0.22-\mu \mathrm{m}$ micropore membrane filter and the toxin was measured by optical density at $280 \mathrm{~nm}$ with UV spectrophotometry (TU-1901). Crude toxin concentration was calculated with a standard curve of bovine serum protein (Ren et al. 2014). All of the above experiments were conducted at least twice. For virulence tests, the seed of sunflower hybrid LD5009 (Kaifurui Seeds Company) were planted in six pots $(12 \mathrm{~cm}$ in diameter by $12 \mathrm{~cm}$ in height) with 5 seeds/ pot. Conidial inoculum was obtained by washing 7-day-old wheat bran culture (in glass pots) with sterile deionized water (Zhang et al. 2017), filtering the suspension through three layers of sterile cheese cloth (grade 50), and adjusting to a final concentration of $1 \times 10^{7}$ conidia/ml. Sunflower seedlings at V2 stage were inoculated with the conidia suspension using the root wound inoculation method (Shi et al. 1993). Briefly, three 6- to 8-cm-deep holes were made triangularly with a fruit knife in the potting mix to wound the fibrous roots. The conidial suspension $(100 \mathrm{ml} / \mathrm{pot})$ was poured into holes. The roots of control plants were inoculated with sterilized distilled water only. All of the pots were kept under a 16-h photoperiod with temperatures of 20 to $25^{\circ} \mathrm{C}$ and $40 \%$ relative humidity. Disease severity was rated 21 days postinoculation (dpi) according to a 0-to-4 scale (Flood et al. 1978), where 0 indicated no evidence of disease symptoms; 1 indicated $<25 \%$ leaves showing wilt symptoms; 2 indicated 25 to $50 \%$ leaves showing wilt symptoms; 3 indicated 50 to $75 \%$ leaves with wilt symptoms; and 4 indicated more than $75 \%$ of leaves with wilt symptoms. Disease incidence (DI) was calculated using the formula DI $=\left[\sum\right.$ (each rating scale $\times$ the corresponding number of seedlings in the rating)/(the highest rating scale $\times$ the total number of seedlings) $] \times 100$.

This trial was repeated for three times. Data from the repeats were analyzed by analysis of variance using the SAS 9.0 (Duncan's new multiple range test). The confidence level of all analyses was set at $95 \%$, and $P<0.05$ was considered to be statistically significant.

Fluorescent microscopic observations. Transformant VdBM9-6 was selected based on its phenotypic similarity to the wild-type strain. Seed of hybrid LD5009 were planted into eight pots (containing a mixture of $1: 1$ [ $\mathrm{vol} / \mathrm{vol}]$ sterilized sand and potting soil), with 4 seeds/pot ( $34 \mathrm{~cm}$ in diameter by $23 \mathrm{~cm}$ in height). Six pots were inoculated with VdBM9-6 and two pots were inoculated with water as control. The pots were kept in the greenhouse with the conditions described in the pathogenicity tests above.

Microscopic examinations started $12 \mathrm{~h}$ postinoculation (hpi), and observations were repeated at 24,48 , and $72 \mathrm{hpi}$ and $7 \mathrm{dpi}$. Aboveground tissues and different parts of inflorescence were also examined by laserscanning microscopy (LSM) after 10 weeks postinoculation (wpi).

At each sampling time, four plants inoculated with VdBM9-6 and one control plant were gently removed from the pot and washed free of soil with distilled water. Each plant was manually sectioned into 12-mm slices transversely or vertically with a double-edged razor blade. In all, 10 sections were prepared from different parts of each sunflower plant, and 5 uniformly thin and unbroken sections best suited for microscopic observation were selected for examination under microscopy. Microscopic analyses of GFP signals were performed with a Zeiss LSM 510 laser-scanning microscope (Zeiss) (GFP: excitation at $488 \mathrm{~nm}$ and emission at $543 \mathrm{~nm}$ ). Digital images acquired from individual channels were merged using the Zeiss LSM Image Examiner.

Detecting pathogen colonization on inflorescence using MNP10 medium. To verify the observation of $V$. dahliae on inflorescence under fluorescence microcopy, the flower and inflorescence were collected from sunflower plants at 12 wpi. With the help of botanists, the different parts of the flower and inflorescence such as phyllaries, receptacle, hull, testa, cotyledon, corolla, anther filament, style, and pollen grains were dissected under an anatomical lens. The dissected fresh tissues were directly placed on modified NP-10 selection 
medium (MNP-10) for culture to observe the colony of $V$. dahliae (Kabir et al. 2004). For each dissected tissue, 20 samples were examined. This experiment was repeated twice.

\section{Results}

Screening GFP-labeled $\boldsymbol{V}$. dahliae transformants for inoculation. Out of 120 putative transformants, 40 were randomly selected and tested for the presence of the hygromycin B and the GFP genes using PCR with respective gene-specific primers (Supplementary Fig. S1A and B). GFP fluorescence was also detected under a microscope to confirm the stable integration of T-DNA into the genome of $V$. dahliae. Transformants varied in colony morphology, growth rate, conidia production, crude toxin concentration, and virulence on sunflower compared with the wild-type strain VdBM9 (Supplementary
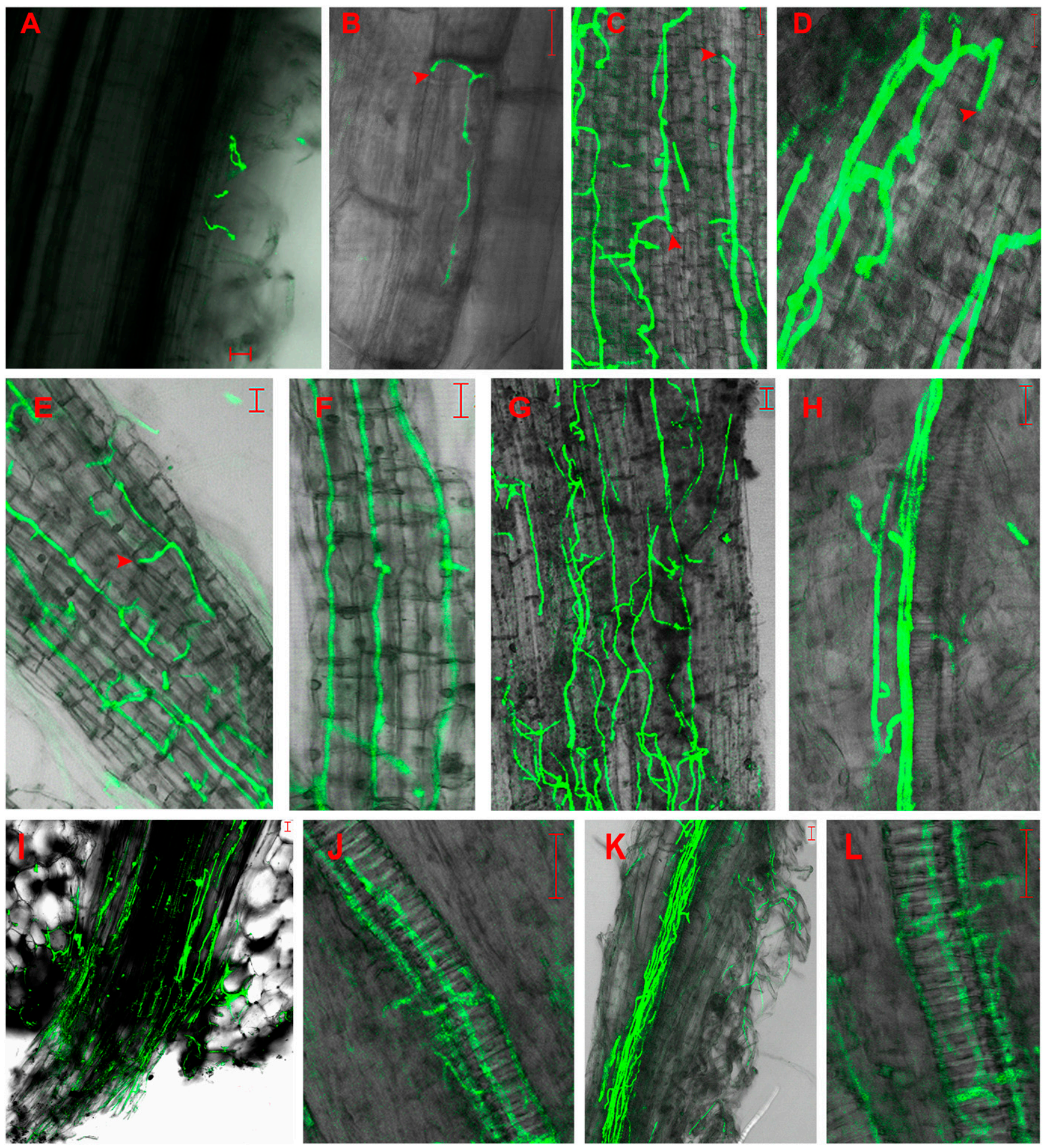

Fig. 1. Germination of conidia of the green fluorescent protein (GFP)-expressing strain VdBM9-6 of Verticillium dahliae and colonization of root system of sunflower seedlings (cultivar LD5009) $24 \mathrm{~h}$ to 7 days postinoculation. A, Germinated conidia on root hairs $24 \mathrm{~h}$ postinoculation (hpi). B, Mycelium extended along the longitudinal junction between root epidermal cells on the elongation zone of lateral root $48 \mathrm{hpi}$. $\mathbf{C}$ and $\mathbf{D}$, Mycelium continued elongating along the longitudinal axis of the root epidermal cells, and mycelium penetrated into adjacent epidermal cell directly without forming any conspicuous infection structure such as appressoria, respectively, 72 hpi. E and $\mathbf{F}$, Mycelium networks formed on the surface of lateral roots 96 hpi. G. Mycelium disorderly formed on the surface of taproot 96 hpi. H, No colonization of the vascular vessels of lateral root $96 \mathrm{hpi}$. I, Massive colonization of mycelium on the junction site of lateral root and taproot $96 \mathrm{hpi}$. J, Mycelia in vascular vessel of lateral root 5 days postinoculation (dpi). $\mathrm{K}$, mycelium extended along the vascular bundle of taproot $7 \mathrm{dpi}$. L, Development of $V$. dahliae in vascular cells of taproot 7 dpi. Analyses of images captured using laserscanning microscopy (LSM); LSM settings for GFP were $488 \mathrm{~nm}$ for excitation and $543 \mathrm{~nm}$ for emission. Arrows denote the penetration sites. Scale bars $=20 \mu \mathrm{m}$. 
Fig. S2). The transformant VdBM9-6 was chosen for subsequent studies because its morphology (Supplementary Fig. S3), biological properties, and virulence were indistinguishable from the wildtype strain.

Colonization process on sunflower roots by GFP-labeled $\boldsymbol{V}$. dahlia. In general, a GFP signal was observed in all sections but the signal intensity varied due to a difference in section thickness. The GFP signal was not observed in any sections from noninoculated (control) plants at any sampling time point (Supplementary Fig. S4). At $12 \mathrm{hpi}$, conidia were observed on the root surface of both taproots and lateral roots but few had germinated. At $24 \mathrm{hpi}$, most conidia had germinated and mycelia were mainly observed on the root hairs of lateral roots (Fig. 1A). At 48 hpi, a few hyphae could be observed on the root epidermis and developing along the longitudinal grooves of epidermal cells of lateral roots (Fig. 1B). At 72 hpi, mycelium expanded in parallel along the epidermal cells of lateral roots and, sometimes, it appeared at the junctions of epidermal cells and penetrated into the epidermal cells of taproots (Fig. 1C and D). At 96 hpi, the lateral roots surface was covered with developed mycelium (Fig. $1 \mathrm{E}$ and $\mathrm{F}$ ). In addition to the disorderly reticular structure that formed on the taproot epidermis (Fig. 1G), some mycelium was detected along the exterior of the vascular bundle in lateral roots at $96 \mathrm{hpi}$ (Fig. 1H). At this time point, the GFP signal was also detected at junction points between the lateral roots and taproots (Fig. 1I). At 5 dpi, mycelium was detected in the xylem vessel of several lateral roots (Fig. 1J). Complete colonization of both inter- and intracellular space of cortical tissue and vascular bundle of taproots was observed by 7 dpi (Fig. $1 \mathrm{~K}$ and L).

Expanding of $\boldsymbol{V}$. dahliae in aboveground tissues of sunflower. After colonization in the vascular bundles of taproot, the mycelium expanded to the aboveground tissues of sunflower via the vascular system. The GFP signal was observed in both the epidermal cells (Fig. 2A and B) and the cortical tissues (Fig. 2C, D, E, and F) at the base of the stem 10 wpi. Meanwhile, colonization was also observed in the xylem vessels of the stem (Fig. $2 \mathrm{G}$ and $\mathrm{H}$ ). At the same time point, both the epidermal cells and vascular bundles of the petiole and leaf vein were also colonized by $V$. dahliae (Fig. 2I, J, K, and $\mathrm{L}$ ).

Detection of $V$. dahliae in different parts of inflorescence. As symptoms progressed, the GFP signals were observed on the different parts of inflorescence such as phyllarie (Fig. 3A), receptacle scale (Fig. 3C), and testa (Fig. 3E) under fluorescence microcopy, whereas the corresponding images showed different parts of inflorescence under bright-field microscopy (Fig. 3B, D, and F). The GFP signal was also detected on a small fraction of pollen grains (Fig. 3G and $\mathrm{H}$ ), indicating that the floral organ can be colonized by the pathogen.

To confirm the observation on inflorescence under epifluorescence microscopy, we placed excised inflorescence tissues collected from inoculated sunflower plants onto MNP-10 medium. After culturing for 7 days, colonies appeared around the corolla, anther
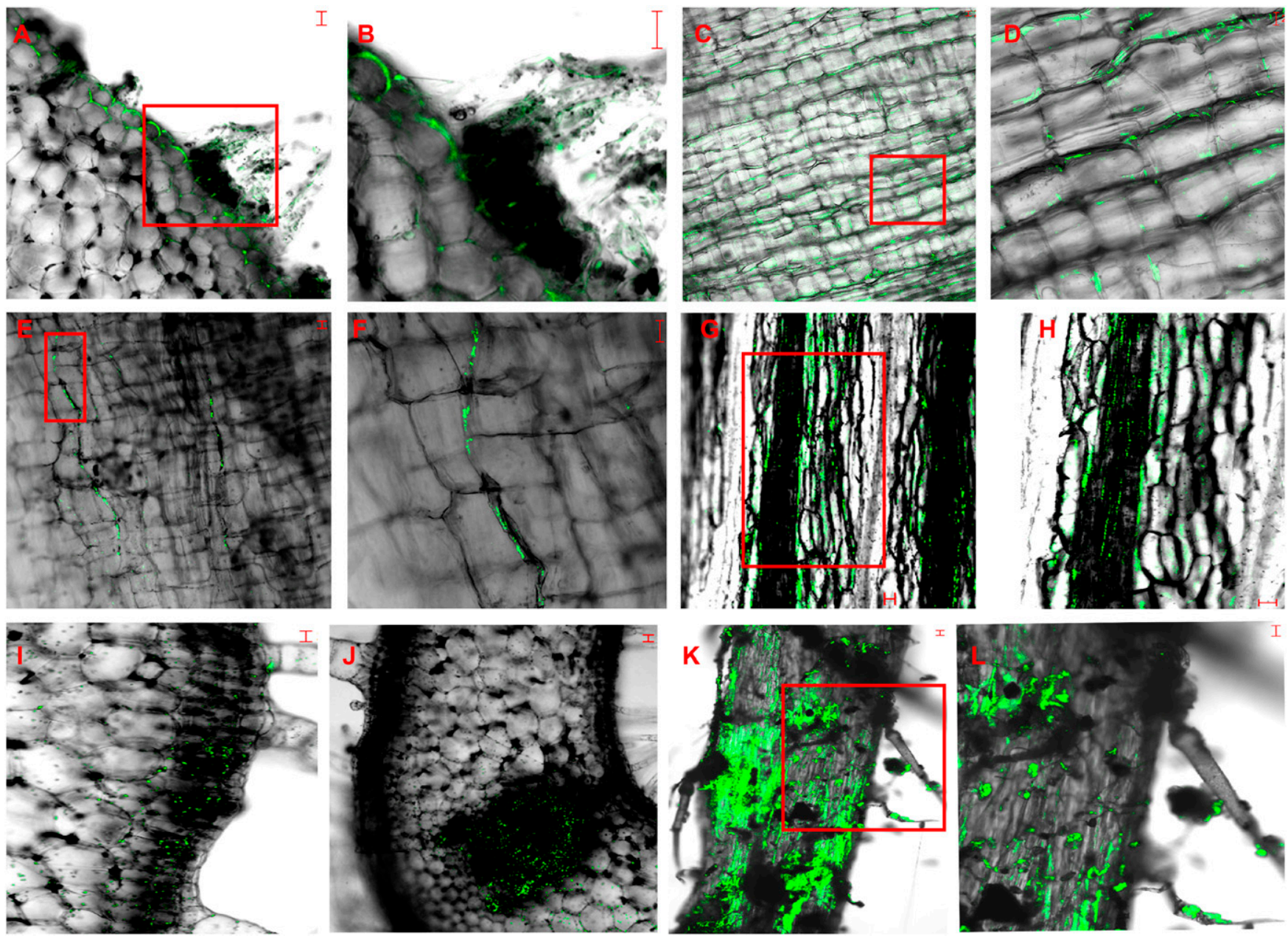

Fig. 2. Systemic colonization of sunflower aboveground tissues by the green fluorescent protein (GFP)-expressing strain VdBM9-6 of Verticillium dahliae (10 weeks postinoculation). A, Cross section of a sunflower stem showing colonization of $V$. dahliae in the epidermal cells. B, Enlargement of box marked in A. C and $\mathbf{E}$, Cross section of a sunflower stem showing colonization of $V$. dahliae in the cortical tissues. D and F, Enlargement of boxes marked in $C$ and $E$, respectively. $\mathbf{G}$, Longitudinal section of a sunflower stem showing colonization of $V$. dahliae in the vascular elements. $\mathrm{H}$, Enlargement of box marked in G. I, Cross section of a petiole showing colonization of $V$. dahliae in the epidermal cells. J, Cross section of a sunflower petiole showing colonization of $V$. dahliae in the vascular elements. K, Strong GFP signals in the epidermal cells of leaf vein. L, Enlargement of box marked in K. Analyses of images captured using laser-scanning microscopy (LSM); LSM settings for GFP were 488 nm for excitation and $543 \mathrm{~nm}$ for emission. Scale bars $=20 \mu \mathrm{m}$. 
filament, style, pollen grain, phyllaries, receptacle, receptacle scale, hull, and testa but not cotyledons. The recovered colonies showed strong GFP signals under fluorescence microscopy, indicating that they were from the inoculated strain VdBM9-6. Colonies were not observed around flower samples collected from control plants (Fig. 4).

\section{Discussion}

Because a GFP-expressing fungal strain can be used as a vital marker to label the infection process of a pathogen on a host, GFPlabeled transformants have become a common tool for analysis of various plant pathogens on oilseed rape (Brassica napus L.) (Eynck et al. 2007), lettuce (Vallad and Subbarao 2008), eggplant (Solanum melongena L.) (Pantelides et al. 2009), spinach (Maruthachalam et al. 2013), cotton (Zhang et al. 2013), and A. thaliana (Reusche et al. 2014; Zhao et al. 2014). To our knowledge, this is the first study of $V$. dahliae infection and colonization in sunflower using a GFPlabeled $V$. dahliae strain.

We observed that GFP-labeled conidia were mainly attached on the root cap, root hairs, and elongation zones of the sunflower roots. Only a few of the hyphae from the germinated GFP-labeled conidia were observed to be attached on the surface of root hairs and continued to develop along the longitudinal grooves of the epidermal cells of lateral roots. This is similar to what was observed in lettuce (Vallad and Subbarao 2008) and A. thaliana (Zhao et al. 2014), where the mycelium developed from conidia expanded along the longitudinal
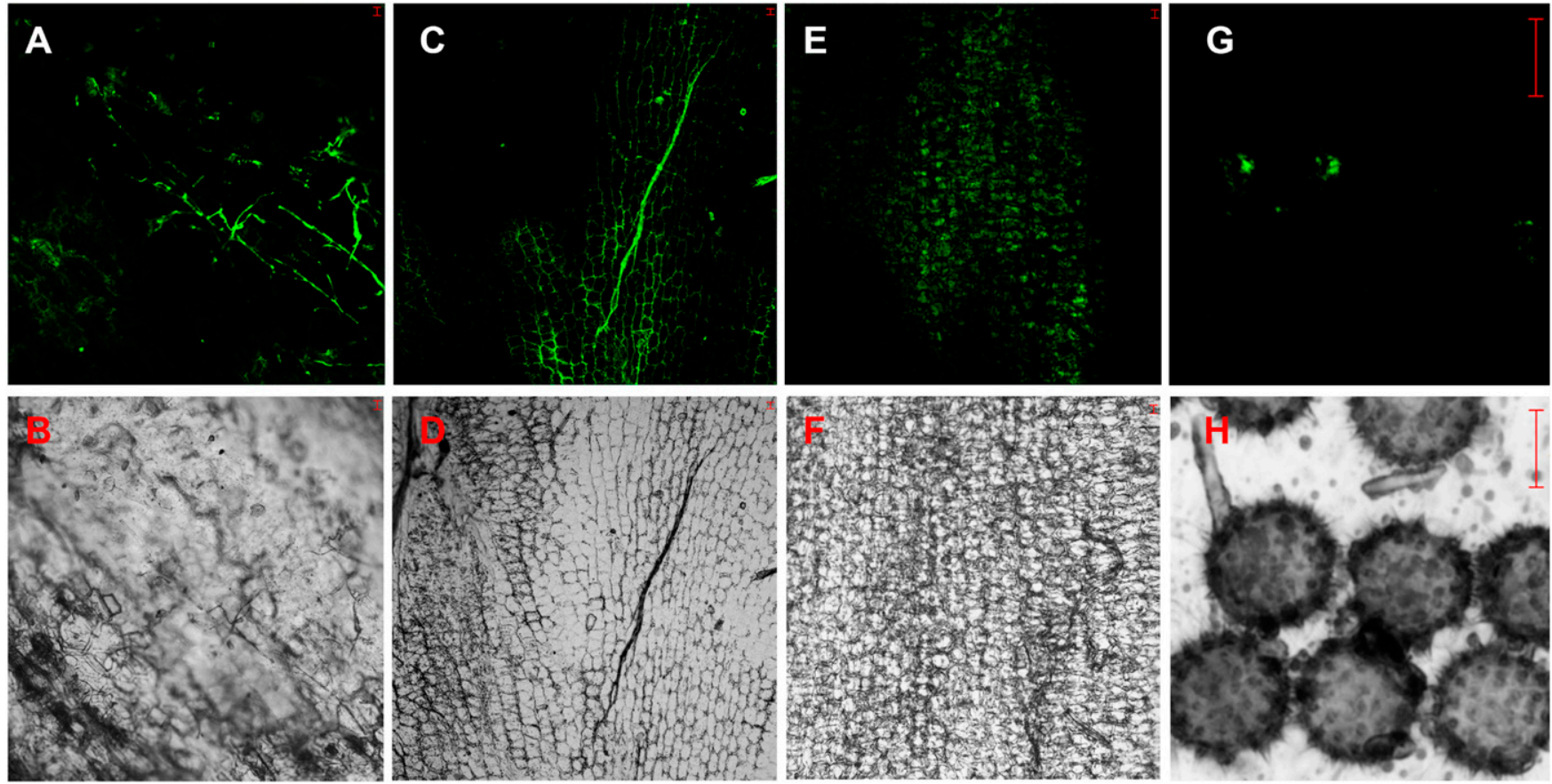

Fig. 3. Colonization of sunflower inflorescence by the green fluorescent protein (GFP)-expressing strain VdBM9-6 (10 weeks postinoculation). A, Colonization on sunflower phyllaries. B, Phyllaries under bright-field microscopy. C, Mycelium network formed on sunflower receptacle scale. D, Receptacle scale under bright-field microscopy. E, GFP signals detected in the testa. F, Testa under bright-field microscopy. G, GFP signals in sunflower pollen grains. H, Pollen grains under bright-field microscopy. Analyses of images captured using laser-scanning microscopy (LSM); LSM settings for GFP were $488 \mathrm{~nm}$ for excitation and $543 \mathrm{~nm}$ for emission. Scale bars $=20 \mu \mathrm{m}$.
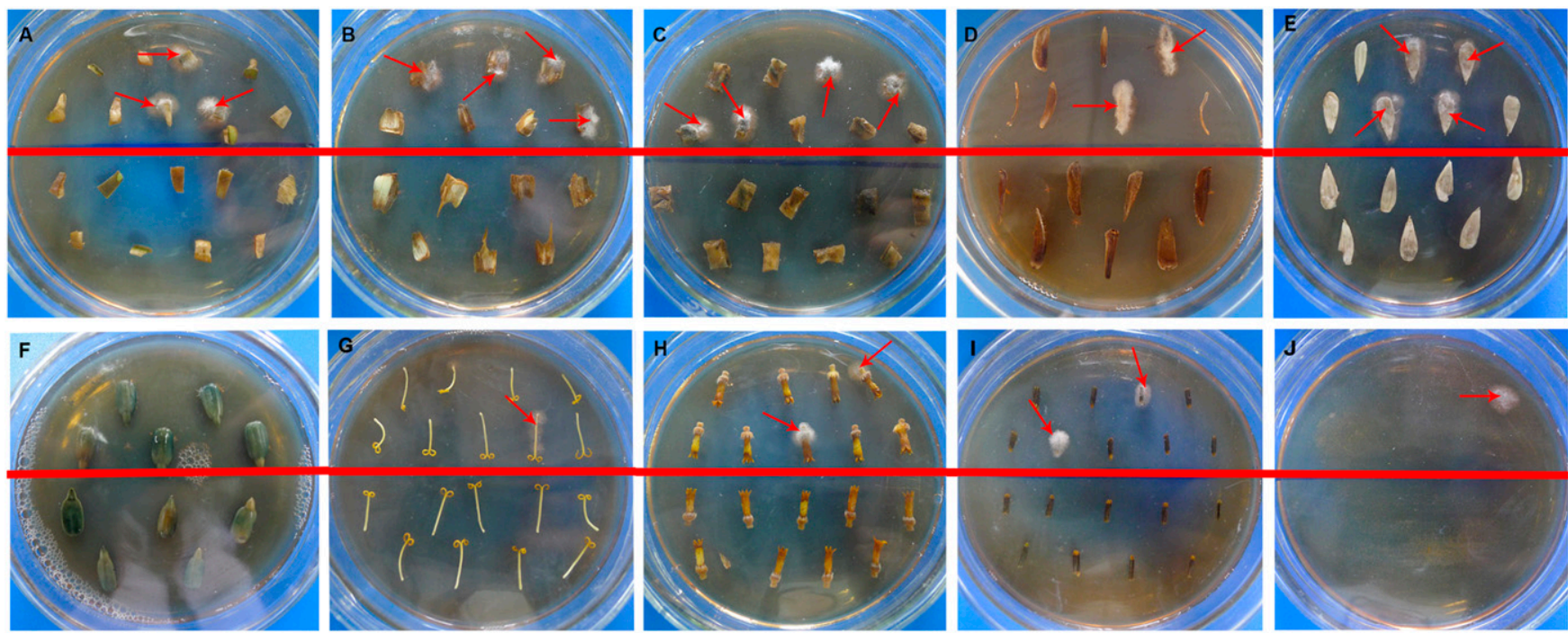

Fig. 4. Detection of contamination of Verticillium dahliae on sunflower inflorescence after 7 days of culture on selective medium MNP-10. Images were captured 10 weeks postinoculation with conidia of V. dahliae on seedling A, phyllaries; B, receptacle scale; C, receptacle; D, hull; E, testa; F, cotyledon; G, corolla; H, anther filament; I, style; and $\mathbf{J}$, pollen grain. Floral tissues from inoculated plants (upper half of the plates) and from noninoculated control plants (lower half of the plates). 
grooves of epidermal cells before it successfully colonized the root cortex (Vallad and Subbarao 2008; Zhao et al. 2014). Also, massive mycelia were observed on elongation zones of the root tips of lateral roots, and a disorderly reticular structure was also formed in the root epidermis in our study. This is in agreement with observations in susceptible lettuce, where colonies of $V$. dahliae established themselves in root elongation zones to produce more elaborate networks of hyphae along the root surface and exhibited growth within the grooves between epidermal cells (Vallad and Subbarao 2008). Additionally, abundant GFP signals were detected at the protrusion sites of taproots in this study, suggesting that these sites are likely be the infected courts for $V$. dahliae and may facilitate systemic root infection. This is verified by findings that emergence of lateral roots leads to leakage of nutrients, thus providing opportunities for propagation of the pathogens (Garber and Houston 1966). However, this is in disagreement with observations using immunohistochemical staining (Zhao and Dai 2009) that $V$. dahliae was not detected at the sites where cotton lateral roots formed.

After successful colonization on the taproot of sunflower, $V$. dahliae quickly expanded to the aboveground parts via the vascular system. GFP signals were detected in the xylem vessels of stem, petiole, and leaf veins of sunflower. This is similar to the $V$. dahliae systematic infection process in oilseed rape (Eynck et al. 2007), lettuce (Vallad and Subbarao 2008), and spinach (Maruthachalam et al. 2013).

Several studies have reported the presence of certain specialized infection structures during the colonization of $V$. dahliae on host roots. During the infection of potato by $V$. dahliae in a hydroponic system, "small protuberances" were reported to develop on hyphae along the longitudinal grooves of epidermal cells that resulted in intracellular infection (Perry and Evert 1983). Zhao et al. (2016) observed some simple penetration structures comprising swollen hyphae known as hyphopodia, an appressorium-like infectious structure, during the process of infection of cotton by $V$. dahliae. In cotton, the hyphal diameter narrowed when it penetrated through the cell walls and returned to normal size after penetration (Zhang et al. 2013). In oilseed rape (Eynck et al. 2007), A. thaliana (Zhao et al. 2014), and sunflower (our observation), hyphae only slightly swollen at the tip were observed when $V$. dahliae invaded root tissues.

Appressoria are a kind of classic infection structure of pathogenic fungi that can overcome the barriers of a host's cell wall. Garber and Houston (1966) reported the presence of appressoria during the infection of cotton roots by V. albo-atrum but only when hyphae developed intracellularly in the epidermis or at the pit border between xylem vessel members. After the inoculation of lettuce roots with $V$. dahliae, the germ tubes of the pathogen extended along root epidermal cells longitudinally and appressoria usually formed within the cell junctions and directly penetrated an adjoining cell (Vallad and Subbarao 2008). The formation of appressoria was also detected on both resistant and susceptible lettuce varieties (Vallad and Subbarao 2008), whereas this was not the case for $V$. dahliae on sunflower, although we did check quite a few slides of roots samples under fluorescence microcopy. It is more likely that the infection structure of $V$. dahliae is variable on different host species and the thigmotropic responses that they elicit may determine whether or not $V$. dahliae forms appressoria or promotes hyphal swelling during colonization on different host root system.

In this study, conidia were not observed during the entire colonization process in vascular bundles of sunflower. This is in contrast with the observations of production of conidia inside the xylem element of oilseed rape (Eynck et al. 2007), within the interior tissues of the developing capitulum of lettuce (Vallad and Subbarao 2008), and in the infected pericarp tissues of spinach (Maruthachalam et al. 2013). The reason for the lack of conidia in interior tissues of sunflower is unknown but a possible explanation is that sunflower plants produce large-diameter stems with many vascular bundles; thus, locating conidia within a single vascular bundle would be difficult. In addition, sunflower is a taller plant (at least $170 \mathrm{~cm}$ ) and, therefore, the long-distance transportation of conidia within nutrition-deficient xylem bundles may not be suitable for conidia survival.
In our study, systematic infection of both inflorescence and testa of seed was confirmed both under fluorescence microscopy and using selective medium MNP-10. This was supported by several previous studies, which observed that microsclerotia can contaminate the exterior of sunflower seed and fungal mycelium such as the pericarp and testa, but not cotyledons, can be detected within seed (Sackston 1980; Sackston et al. 1957). V. albo-atrum was detected only on a few receptacles, one immature seed attached by adhering calyx, and one fully matured sunflower seed (Sackston and Martens 1959); V. dahliae was also confirmed to colonize the pericarp and testa of some safflower seed (Klisiewicz 1975), and pappus, pericarp, integument, and endosperm of lettuce seed (Vallad and Subbarao 2008). Contaminated seed can be the main reason for long-distance dispersal of the seedborne pathogens (Allen 1951; du Toit et al. 2005; Kadow 1934; Klisiewicz 1975; Maruthachalam et al. 2013); this is also the case for the transmission of $V$. dahliae. The contaminated testa of sunflower by $V$. dahliae will facilitate the transmission of pathogens both domestically and internationally via seed transportation. This finding illustrates the importance of treating sunflower seed with proper fungicides for controlling sunflower Verticillium wilt in the future.

\section{Acknowledgments}

We thank B. Zhang (Jiangsu Academy of Agricultural Sciences, Nanjing, China) for kindly providing the binary vector pGH-sGFP and M. S. Goettel (Research Scientist, Insect Pathology, Lethbridge Research Center, Agriculture and Agri-Food Canada [Retired]) for discussion and revision of an early version of this article.

\section{Literature Cited}

Allen, R. M. 1951. Cotton seeds are capable of carrying Verticillium. Plant Dis. 35: $11-12$

Devaux, A., and Sackston, W. E. 1966. Taxonomy of Verticillium species causing wilt of horticultural crops in Quebec. Can. J. Bot. 44:803-811.

Dobinson, K. F., Grant, S. J., and Kang, S. 2004. Cloning and targeted disruption, via Agrobacterium tumefaciens-mediated transformation, of a trypsin protease gene from the vascular wilt fungus Verticillium dahliae. Curr. Genet. 45: 104-110.

du Toit, L. J., Derie, M. L., and Hernandez-Perez, P. 2005. Verticillium wilt in spinach seed production. Plant Dis. 89:4-11.

Eynck, C., Koopmann, B., Grunewaldt-Stoecker, G., Karlovsky, P., and von Tiedemann, A. 2007. Differential interactions of Verticillium longisporum and V. dahliae with Brassica napus detected with molecular and histological techniques. Eur. J. Plant Pathol. 118:259-274.

Fitzell, R., Evans, G., and Fahy, P. C. 1980. Studies on the colonization of plant roots by Verticillium dahliae Klebahn with use of immunofluorescent staining. Aust. J. Bot. 28:357-368.

Flood, J., Isaac, L., and Milton, J. W. 1978. Reactions of some cultivars of lucerne to various isolates of Verticillium albo-atrum. Plant Pathol. 27:166-169.

Garber, R. H., and Houston, B. R. 1966. Penetration and development of Verticillium albo-atrum in the cotton plant. Phytopathology 56:1121-1126.

Harveson, R. M., Markell, S. G., Block, C. C., and Gulya, T. J. 2016. Compendium of Sunflower Diseases, 1st ed. American Phytopathological Society, St. Paul, MN

Hoes, J. A., and Putt, E. D. 1963. Sunflower disease in Manitoba in 1963. Ltc Callbeck.

Kabir, Z., Bhat, R. G., and Subbarao, K. V. 2004. Comparison of media for recovery of Verticillium dahliae from soil. Plant Dis. 88:49-55.

Kadow, K. J. 1934. Seed transmission of Verticillium wilt of eggplants and tomatoes. Phytopathology 24:1265-1268.

Klisiewicz, J. M. 1975. Survival and dissemination of Verticillium in infected safflower seed. Phytopathology 65:696-698

Lan, W. W., Chen, Q., Wang, W. J., and Wu, X. H. 2009. Advances in the sunflower Alternaria black spot and its integrated management. Plant Prot. 35:24-29. (In Chinese)

Markell, S., Harveson, R., Block, C., and Gulya, T. 2015. Sunflower Disease Diagnostic Series. North Dakota State Coop. Ext. Serv. Publ. PP1727.

Maruthachalam, K., Klosterman, S. J., Anchieta, A., Mou, B., and Subbarao, K. V. 2013. Colonization of spinach by Verticillium dahliae and effects of pathogen localization on the efficacy of seed treatments. Phytopathology 103: 268-280.

Pantelides, I. S., Tjamos, S. E., Striglis, I. A., Chatzipavlidis, I., and Paplomatas, E. J. 2009. Mode of action of a non-pathogenic Fusarium oxysporum strain against Verticillium dahliae using real time $\mathrm{qPCR}$ analysis and biomarker transformation. Biol. Control 50:30-36.

Perry, J. W., and Evert, R. F. 1983. The effect of colonization by Verticillium dahliae on the root tips of. Can. J. Bot. 61:3422-3429.

Ren, J., Zhang, G., Cao, X., Zhou, H. Y., Jing, L., and Zhao, J. 2014. Crude toxin production ability and pathogenicity differentiation on sunflower Verticillium dahliae. Chin. J. Oil Crop Sci. 36:393-397. 
Reusche, M., Truskina, J., Thole, K., Nagel, L., Rindfleisch, S., Tran, V. T., BrausStromeyer, S. A., Braus, G. H., Teichmann, T., and Lipka, V. 2014. Infections with the vascular pathogens Verticillium longisporum and Verticillium dahliae induce distinct disease symptoms and differentially affect drought stress tolerance of Arabidopsis thaliana. Environ. Exp. Bot. 108: 23-37.

Sackston, W. E., McDonald, W. C., and Martens, J. 1957. Leaf mottle or Verticillium wilt of sunflower. Plant Dis. Research Report. 41:337-343.

Sackston, W. E. 1980. Some factors influencing infection of sunflower seed by Verticillium dahliae. Can. J. Plant Pathol. 2:209-212.

Sackston, W. E., and Martens, J. W. 1959. Dissemination of Verticillium alboatrum on seed of sunflower (Helianthus annuus). Can. J. Bot. 37:759-768.

Selden, R. F., and Schatz, D. G. 1989. Analysis of DNA sequences by blotting and hybridization. Pages 75-79 in: Short Protocols in Molecular Biology. F. M. Ausubel, R. Brent, R. E. Kingston, D. D. Moor, and J. G. Seidman, eds. Wiley, New York.

Shi, L. Y., Wang, B., Shi, L. Y., Wang, B., and Wen, X. 1993. Study on the differentiation and cultural characteristics of Verticillium dahliae on cotton in China. J. Plant Prot. 3:247-252.
Stewart, J. C. N., and Via, L. E. 1993. A rapid CTAB DNA isolation technique useful for RAPD fingerprinting and other PCR applications. Biotechniques 14:748-750. Vallad, G. E., and Subbarao, K. V. 2008. Colonization of resistant and susceptible lettuce cultivars by a green fluorescent protein-tagged isolate of Verticillium dahliae. Phytopathology 98:871-885.

Zhang, J., Zhang, G., Zhang, Y. Y., Lu, S. Z., and Zhao, J. 2017. The establishment of T-DNA library and the characterization of positive transformants of sunflower Verticillium dahliae. J. Plant Prot. 44:223-231.

Zhang, W. W., Jiang, T. F., Cui, X., Qi, F. J., and Jian, G. L. 2013. Colonization in cotton plants by a green fluorescent protein labelled strain of Verticillium dahliae. Eur. J. Plant Pathol. 135:867-876.

Zhao, F. G., and Dai, X. F. 2009. Infection process of Verticillium dahliae Klebahn in cotton. Genomics Appl. Biol. 28:786-792.

Zhao, P., Zhao, Y. L., Jin, Y., Zhang, T., and Guo, H. S. 2014. Colonization process of Arabidopsis thaliana roots by a green fluorescent protein-tagged isolate of Verticillium dahliae. Protein Cell 5:94-98.

Zhao, Y. L., Zhou, T. T., and Guo, H. S. 2016. Hyphopodium-specific VdNoxB/ VdPls1-dependent ROS-Ca2+ signaling is required for plant infection by Verticillium dahliae. PLoS Pathog 12:e1005793. 